\title{
PREDICADOS SECUNDÁRIOS: RESTRIÇÕES SEMÂNTICAS
}

\author{
Maria José Foltran*
}

\section{Introdução}

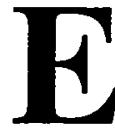

m Foltran (1999), argumentei que não é possível explicar a restrição que opera sobre os predicados secundários somente pela estrutura lexical ou pela propriedade de afetação, como alegam alguns autores (Rapoport, 1990, por exemplo). Em vez disso, pude observar que são as propriedades stagel individual level dos dois predicados e a conexão que se estabelece entre ambos por meio de uma regra de interpretação que permite explicar tais construções. A regra semântica estabelece essa conexão pelas de funções sobre intervalos de tempo e localização dos eventos. As informações relevantes para a interpretação estão presentes na estrutura aspectual de seus elementos e uma regra de interpretação semântica permite o processamento.

Assim, teríamos uma estrutura canônica formada por dois predicados stage level, em que o predicado secundário inclui temporalmente o predicado principal, como mostra o exemplo em (1).

* Universidade Federal do Paraná. 
(1) Ele comeu a carne crua.

A única construção não interpretada pela gramática seria a combinação de predicados individual + individual level, pois nenhum dos predicados poderia funcionar como restritor temporal, exigência desse tipo de construção. A sentença em (2) é um exemplo dessa ocorrência (a inaceitabilidade diz respeito à leitura do adjetivo como predicativo).

(2) *Eu gosto do meu café brasileiro.

Uma evidência contra essa análise aparece em Santos (2000), em que se explica a agramaticalidade de uma construção de predicação secundária como (3), justo a estrutura que havíamos considerado canônica.

(3) *Ele entrou em pânico assaltado.

O trabalho de Santos (2000), mostra que construções participiais absolutas sem DP realizado permitem tanto uma leitura eventiva perfectiva quanto uma leitura de predicado secundário, quando ocorrem formas participiais que denotam propriedades. Os particípios que mantêm a memória do evento não permitem a leitura de predicado secundário.

Meu objetivo, neste trabalho, é mostrar que as noções assumidas por Santos não são consistentes do ponto de vista semântico e que uma teoria de intervalos de tempo propicia uma explicação mais adequada ao fato de uma forma participial como assaltado não poder ocorrer numa construção de predicação secundária.

\section{A análise de Santos (2000)}

Segundo Santos (2000), há um consenso em se classificar (4) como construção de Particípio Absoluto, o que não acontece com (5), que, para alguns, está excluída dessas estruturas. A diferença relevante entre as duas estruturas é a presença de um argumento interno realizado em (4) e não em (5).

(4) Vencido o inimigo, começou a festa. 
Como nosso interesse está voltado para as sentenças do tipo que ocorre em (5), ou seja, nas participiais sem DP realizado, não vamos nos deter em apresentar diferenças mais significativas entre (4) e (5).

Santos argumenta que as construções do tipo (5) apresentam três interpretações possíveis. A primeira é a interpretação obrigatória de particípio absoluto com DP realizado, que é uma interpretação perfectiva. A segunda, uma interpretação durativa, denota um tempo simultâneo ao que é denotado pela subordinante. Finalmente, a terceira assemelha-se à interpretação típica de um predicado secundário. A diferença essencial entre elas, segundo Santos, diz respeito à eventividade. Na perfectiva e na durativa, o particípio é interpretado como denotando o estado resultante de um evento, preservando a capacidade de ser associado a um evento independente daquele que é denotado pela subordinante. Nas participiais predicativas, o particípio é tomado como uma propriedade de uma entidade, ou seja, um estado. Essa interpretação não inclui a memória de que se trata de um estado resultante de um evento. A partir da construção em (6)a, apresentamos as três interpretações possíveis.
a. Salteadas, as batatas começaram a secar.
b. Depois de salteadas, as... (eventiva - perfectiva).
c. Estando a ser salteadas, as... (eventiva - durativa).
d. Estando salteadas, as... (predicativa).

Santos reconhece que a distinção entre as interpretações perfectiva e predicativa não é óbvia, na medida em que ambas correspondem à interpretação da participial como um estado. No entanto, essas construções apresentam diferentes propriedades sintáticas e semânticas, ou seja, a distinção é empiricamente motivada.

A primeira propriedade apresentada é o fato de a interpretação predicativa só poder ser possível quando o estado resultante do evento denotado pelo particípio puder ser interpretado como uma propriedade atribuível a uma entidade. A impossibilidade da terceira interpretação em (7)d deve-se ao fato de assaltado não aceitar facilmente a interpretação como propriedade de uma entidade.

\footnotetext{
(7) a. Assaltado, o Luís entrou em pânico.

b. Depois de ser assaltado, o...
} 
c. Estando a ser assaltado, $0 . .$.

d. *Estando assaltado, o...

A autora considera o fato de a possibilidade de bloqueio de uma da interpretações não afetar a outra como prova da independência das duas.

Outro argumento apresentado a favor dessa distinção diz respeito aos efeitos provocados pela inclusão nas participiais de advérbios ou expressões adverbiais temporais pontuais e não pontuais. Na presença de um advérbio pontual, a interpretação predicativa é bloqueada ou torna-se marginal. Ao contrário, se se verificar na participial a presença de uma expressão adverbial não pontual, a interpretação predicativa é a preferida. Os exemplos em (8) e (9) demonstram isso.

(8) a. Maquiada no início da tarde, a Maria conseguiu disfarçar o sinal no nariz.

b. Depois de ter sido maquiada no início da tarde,...

c. ??/* Estando maquiada no início da tarde,...

a. Maquiada desde que se levantou, a Maria conseguiu disfarçar o sinal no nariz.

b. ??/* Depois de ter sido maquiada desde que se levantou,...

c. Estando maquiada desde que se levantou,...

Segundo Santos, enquanto um advérbio pontual focaliza um ponto de culminação, precisamente o ponto de culminação de que resulta o estado descrito pelo particípio, um advérbio não pontual focaliza o prolongamento do estado descrito pelo particípio, esquecendo o ponto de culminação que precede esse estado, favorecendo assim a interpretação predicativa. Isso explica a estranheza de (10), em que um particípio que bloqueia a interpretação predicativa co-ocorre com uma expressão adverbial durativa.

(10) Assaltado desde as três horas, o Luís entrou em pânico.

Deve-se notar ainda que as participiais com leitura predicativa permitem clivagem, ao contrário do que acontece com as outras. Na clivagem, as leituras eventivas (perfectiva e durativa) são bloqueadas. 
a. Foi assaltado que o Luís entrou em pânico.

b. Foi maquiada que a Maria espirrou.

Diante desses fatos empíricos, Santos vai propor que a ambigüidade observada nessas construções se manifesta em termos de estruturas sintáticas diferentes, representantes das leituras eventiva e predicativa. A estrutura relacionada a participiais predicativas corresponderia a uma estrutura de predicados secundários: um predicado secundário orientado para o sujeito tem de se encontrar no domínio de IP, enquanto que um predicado secundário orientado para o objeto encontra o seu sujeito em VP. Isso explicaria a agramaticalidade de (12)d.
a. Furioso ${ }_{i}$, o João encontrou a Maria.
b. $O$ João ${ }_{i}$ encontrou a Maria furioso ${ }_{i}$.
c. $O$ João encontrou a Maria furiosa.
d. *Furiosa, o João encontrou a Maria.

Santos conclui a esse respeito que, embora uma participial eventiva possa ocorrer à direita da subordinante, é mais natural que ocorra à sua esquerda, sendo esta a ordem típica neste tipo de construção. Ao contrário, um predicado secundário pode ocorrer à esquerda ou à direita do material oracional restante, sendo que apenas no último caso pode ser interpretado como orientado para o objeto direto. Além disso, podemos constatar diferenças prosódicas: quando ocorrem à esquerda, tanto uma participial eventiva como um predicado secundário devem ser seguidos de uma pausa marcada; à direita, uma participial eventiva é obrigatoriamente precedida por uma pausa, enquanto um predicado secundário pode ou não ser precedido por esse tipo de pausa. Isso acarreta que, quando anteposta, uma participial sem DP realizado pode ser ambígua entre uma leitura de predicado secundário e uma leitura eventiva; mas a mesma participial recebe preferencialmente uma leitura de predicado secundário quando ocorre à direita da subordinante.

(13) Os tanques puseram-se em fuga (,) estilhaçados.

Int. 1: Os tanques puseram-se em fuga estando estilhaçados. [preferencial]

Int. 2: Os tanques puseram-se em fuga depois de estilhaçados.[marginal]

(14) Estilhaçados, os tanques puseram-se em fuga.

Int. 1: Depois de estilhaçados, os tanques puseram-se em fuga. [preferencial] 
Int. 2:Estando estilhaçados, os tanques puseram-se em fuga.

Segundo Santos, essa influência da ordem na interpretação pode ser tomada como uma manifestação de uma tendência universal nas línguas que é referida por Comrie (1989) como a tendência que espelha, pela ordem linear, a ordem temporal dos eventos. Como certos efeitos são explicáveis em termos de ordenação de eventos e como os mesmos efeitos não afetam a posição de participiais predicativas (a leitura predicativa obtém-se quando a leitura perfectiva é tornada marginal pelos efeitos de ordenação dos eventos), isso torna-se um argumento para dizer que a leitura de uma participial predicativa não é uma leitura eventiva. Essa análise explica a agramaticalidade de (15): uma participial que não possa ter uma leitura predicativa dificilmente ocorrerá numa posição de final de frase, posição típica de um predicado secundário.

*O Luís entrou em pânico (,) assaltado.

\section{Caracterização de predicado secundário}

A análise de Santos é bastante convincente em relação à possibilidade de interpretar as participiais sem DP realizado ora como particípio absoluto, ora como predicado secundário. $\mathrm{O}$ meu interesse nessa análise diz respeito especificamente à caracterização dos predicados secundários. É nessa caracterização que considero as opções teóricas de Santos um tanto controversas, ao contrário da análise empírica. Nossa intenção é optar por noções semânticas mais consistentes.

Refiro-me precisamente ao traço que diferencia os adjetivos participiais que permitem uma interpretação de predicado secundário daqueles que permitem só a interpretação de particípio absoluto. Santos reconhece que a distinção entre uma participial perfectiva e predicativa não é óbvia, porque ambas partem do pressuposto de que se trata de um estado. Passa então a falar em eventiva e predicativa. A eventiva é um estado que preserva a capacidade de ser associado a um evento, enquanto que a predicativa denota uma propriedade. Acho que essa distinção também não é óbvia. Precisamos admitir que temos dois tipos de estados: um que guarda a memória do evento, como é o caso de "assaltado"; 
outro que não inclui a memória de que se trata de um estado resultante de um evento. Essa distinção é frágil e, possivelmente, não poderia ser mantida em diferentes contextos.

Buscando caracterizar melhor essas formas participiais para dar conta de seu comportamento diferente, levantei a hipótese de que a noção relevante envolvida nesses casos seriam as de predicados individual level e predicados stage level. Em Foltran (1999), observei que o adjetivo capaz de figurar numa construção de predicação secundária é preferencialmentedo tipo stage level. Isso explicaria a assimetria entre

a. João comprou [um cachorro $]_{i}\left[\right.$ doente $_{i}$.

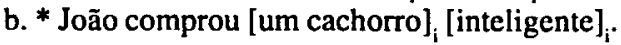

Essa restrição explica a impossibilidade de se usar um NP como predicado nesse contexto, já que NPs, quando predicados, são sempre do tipo individual level.

a. *João comeu a carne um belo pedaço.

b. *Eu encontrei Carlos um professor. ${ }^{1}$

Para sustentar a análise de Santos, tentei traçar um paralelo entre predicados individual level e estados que denotam propriedade por um lado, $\mathrm{e}$ predicados stage level e estados que preservam a memória do evento. Dessa forma, estaríamos afirmando que os adjetivos que expressam propriedade e, portanto, admitem interpretação predicativa, são do tipo individual level. No entanto, essa relação não se sustenta. Isso pode ficar mais claro se retomarmos alguns exemplos de Santos.

a. Maquiada, a Maria conseguiu disfarçar o sinal no nariz.

b. Estando maquiada, a Maria conseguiu disfarçar o sinal no nariz.

c. A Maria conseguiu disfarçar o sinal no nariz maquiada.

a. Assaltado, o Luís entrou em pânico.

b. *Estando assaltado, o Luís entrou em pânico.

c. ${ }^{*} \mathrm{O}$ Luís entrou em pânico assaltado.

1 Em outros contextos, que não o de predicação secundária, os NPs podem ser usados como predicados.

(i) Eu considero este um belo pedaço de bolo.

(ii) Carlos é um professor. 
No exemplo (18), o predicado secundário maquiada é uma forma participial que expressa um propriedade e, ao mesmo tempo, caracteriza-se como predicado stage level, já que predica não do indivíduo, mas de um estágio do indivíduo. $\mathrm{O}$ exemplo (19) se mostra avesso à interpretação de predicado secundário, apesar de a forma participial também ser um predicado stage level.

Não parece ser, portanto, esse tipo de propriedade que está em jogo. Tanto (18) como (19) apresentam características muito próximas: os adjetivos participiais são do tipo stage level, e o predicado matriz também. Como observei em Foltran (1999), essas seriam as propriedades ideais da estrutura para licenciar uma construção de predicação secundária. Reconheci, no entanto, já naquela época, que "só as propriedades individual/stage não explicam as restrições em questão e, também, não dão conta da interpretação que se atribui a uma construção de predicação secundária" (p. 172). O que enfatizei, naquele trabalho, foi o fato de que a interpretação de uma sentença de predicação secundária não depende só do verbo ou do predicado adjetivo, mas de uma conexão entre ambos. Isso valeria tanto para os predicados secundários orientados para 0 sujeito como para os predicados secundários orientados para o objeto (os depictivos). Naquele trabalho, eu buscava uma forma de explicar por que, em alguns casos, era possível um predicado individual level numa construção de predicação secundária. Neste trabalho, a partir da análise de Santos, a situação é exatamente contrária: o que explica a agramaticalidade de um predicado stage level nesse mesmo tipo de construção. $O$ interessante é que posso usar a mesma explicação para ambos os casos.

McNally (1997) sugere que a distinção individual/stage level seja vista em termos de uma inferência de continuidade temporal (temporal persistence). Propriedades individual level carregam uma inferência de que vigoram de forma contínua em relação às entidades a que se aplicam (geralmente sobre um período estendido no tempo). Propriedades stage level não apresentam tal inferência.

Uma outra característica é que propriedades individual level não se atrelam a um lugar. Qualquer localização externa ao indivíduo é irrelevante. Por exemplo, se alguém é ingênuo, essa propriedade segue essa pessoa onde quer que ela vá. Essa característica pode se aplicar também a propriedades stage level, mas não de forma generalizada. Uma pessoa não deixa de "estar gripada" se trocar de lugar. Já outras propriedades stage estão fixadas a uma localização. Por exemplo, se estamos sentados ao computador e saímos, não temos mais a propriedade de "estar sentado ao computador". 
Tendo isso em vista, McNally sugere que, para certos predicados $\mathrm{P}^{1}$ (todos tirados da categoria dos stage level), $\operatorname{loc}\left(\mathrm{P}^{1}, x\right)$ será o valor simples de $\ell$, o subconjunto das localizações espaciais no domínio de interpretação. No entanto, para outros predicados stage level e para todos os individual level, loc $\left(\mathrm{P}^{\mathbf{1}}, x\right)$ será uma outra função, chamada $x$-loc, cujo valor quando aplicado a um par entidade/intervalo dá a localização $(\ell$ ) daquela entidade naquele intervalo.

$$
\text { (20) } x-\operatorname{loc}(x, t)=\ell
$$

A função $x$-loc ajuda a recuperar o fato de que uma propriedade acompanha o indivíduo, sem tornar impossível atribuir, em qualquer tempo dado, um espaço real no qual esse indivíduo apresenta tal propriedade. Assim, também, é possível relacionar um parâmetro espaço-temporal a uma propriedade individual level.

Se o valor da função de localização associada com a atribuição de uma propriedade individual level é, em si, uma função (do tipo $x$-loc) cujo valor depende da escolha de um intervalo temporal, enquanto que a atribuição de propriedade não depende da escolha de um intervalo, obtemos o efeito de que a propriedade se aplica ao indivíduo em nenhuma localização em particular ou, mais precisamente, onde quer que ele possa estar no tempo.

O poder de dar uma localização específica a uma atribuição de propriedade individual level num intervalo (em termos de $x$-loc) é crucial para licenciar predicados secundários, já que uma regra exigiria uma sobreposição entre o valor de loc do par argumento/predicado principal e o do par argumento/ predicado secundário.

Para McNally, essa é a regra semântica de interpretação dos predicados secundários. Essa regra trata esse predicado, essencialmente, como uma função de propriedades a propriedades que serve para restringir o intervalo sobre o qual a propriedade identificada pelo predicado principal se interpreta. Essa regra requer, ainda, que haja uma sobreposição dos espaços em que se dão o predicado principal e o secundário. Apresentamos, a seguir, a estrutura sintática associada com sua forma lógica defendida pela autora e a formalização da regra de interpretação semântica. 


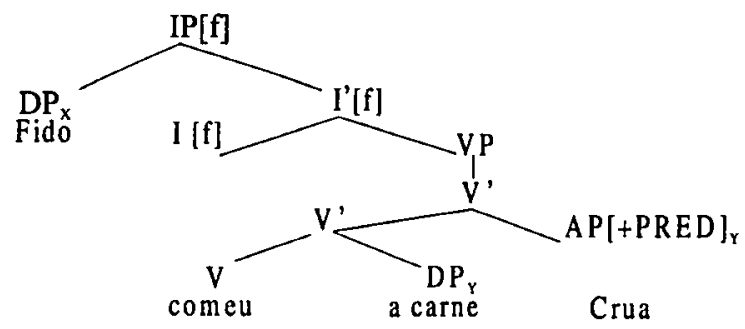

(22) $\left[\left[\left[\mathrm{V}_{1}^{\prime}, \mathrm{XP}[+\mathrm{PRED}] \mathrm{x}_{\mathrm{i}}\right] \mathrm{V}_{2}^{\prime}\right]\right]$ is a function $\mathrm{f}$ of the same sort as $\left[\left[V_{1}^{\prime}\right]\right]$, such that for all $y \in \operatorname{ext}_{<w, 1, b}\left(\left[\left[V_{1}{ }_{1}\right]\right]\right), y \in \operatorname{ext}_{<w, t, b}(f)$ iff int ([[V'] $]], y) \leq_{T}$ int $\left([[\mathrm{XP}[+\mathrm{PRED}]]], \mathrm{x}_{\mathrm{i}}\right)$ and there is some $\ell$ such that $\operatorname{loc}\left(\left[\left[\mathrm{V}_{1}\right]\right], \mathrm{y}\right) \wedge \operatorname{loc}\left([[\mathrm{XP}[+\mathrm{PRED}]]], \mathrm{x}_{\mathrm{i}}\right)=\ell$.

Para entendermos melhor, vamos considerar o exemplo (23).

(23) Fido comeu a carne crua.

[[Comer]] se combina com [[a carne]] e o resultado é uma função proposicional de 1 lugar, cuja extensão em algum índice é o conjunto das entidades que comeram carne. A combinação dessa função proposicional com a função identificada pelo predicado secundário leva a uma nova função proposicional de 1 lugar [[comeu a carne crua]], cuja extensão será um subconjunto da extensão de [[comeu a carne]]: o subconjunto dos comedores de carne que comeram a carne em questão quando estava crua. Se a única carne que Fido comeu estava cozida, Fido não está na extensão de "comeu a carne crua", pois, int([[comeu a carne $],{ }^{2}$ [[Fido]]) não é um subintervalo de int([[crua]], [[a carne]]). A regra diz que $\operatorname{int}(\mathrm{f}, \mathrm{y}$ ) ( a função que se aplica ao predicado principal ( $\mathrm{f}=\mathrm{IP}$ ) não pode ser maior do que o intervalo sobre o qual a relação de atribuição entre o predicado secundário e seu argumento se interpreta. Conceptualmente, esse intervalo pode ser menor: a carne que Fido comeu possivelmente estaria crua antes de ele comê-la ( e poderia continuar crua quando ele terminasse de comer). Portanto, a

2 int corresponde a intervalo. 
autora propõe que seria razoável supor que $\operatorname{int}(f, y)$ seria o encontro de $\operatorname{int}\left(\left[\left[\mathrm{V}^{\prime}\right]\right]\right.$, y) com o intervalo dado por [[XP [+PRED] ]] ao se aplicar a seu argumento.

Dessa forma, assegura-se um parâmetro espaço-temporal para todos os tipos de predicado. Assim, não precisamos apelar para a ambigüidade lexical para dar conta do fato de que, algumas vezes, predicados individual-level se comportam como stage-level. Portanto, o exemplo em (24) (em que um predicado individual level apresenta a interpretação stage level) ocorre sem nenhum problema.

Ele partiu para a Europa ingênuo e voltou depravado.

No meu entender, não é somente a função int ([[XP [+PRED] ]] que vai garantir a interpretação stage do predicado secundário em (24), pois a regra afirma apenas que o resultado da função int $\left(\left[{ } \mathrm{V}_{1}{ }_{1}\right]\right.$ ly) deve ser apenas menor ou igual e, assim, o predicado secundário pode ser um período estendido no tempo. O que vai, na verdade, garantir a interpretação stage é essa condição sobre intervalos de tempo, associada com a regra $\operatorname{loc}\left(\mathrm{P}^{\mathrm{I}}, \mathrm{x}\right)$. Dessa forma, a continuidade temporal do predicado tem um limite e esse limite será dado pelo espaço, já que a regra prevê que os dois espaços devem se sobrepor.

Outra vantagem do tratamento de McNally é o fato de essa abordagem em termos de uma inferência de continuidade temporal licenciar um exemplo como (24) e, ao mesmo tempo, descartar uma sentença como a de (25).

\#Eu gosto do meu café brasileiro.

Razões pragmáticas explicariam a impossibilidade de predicados secundários individual level restringirem predicados principais individual level: estaríamos usando uma atribuição de uma propriedade de continuidade temporal para restringir um intervalo sobre o qual vigora outra propriedade do mesmo tipo. Se ambas as propriedades são tomadas para persistir indefinidamente, não obteríamos uma interpretação útil: a relação de atribuição associada com o predicado secundário não realizaria nenhuma restrição temporal nem o predicado principal teria as características aspectuais que facilitariam a interpretação.

O que precisamos explicar agora é por que um predicado stage level do tipo assaltado não é licenciado nesse tipo de estrutura. Vimos que a função que se aplica ao predicado principal (int $(\mathrm{f}, \mathrm{y}))$ deve resultar num intervalo de tempo que não pode ser maior do que o intervalo sobre o qual a relação de atribuição 
entre o predicado secundário e seu argumento se interpreta. Voltemos à sentença (19)c, retomada aqui como (26). *O Luís entrou em pânico assaltado.

O predicado assaltado denota um intervalo de tempo muito curto (característica dos predicados pontuais do tipo achievements), impossível de incluir o intervalo de tempo do predicado principal. E, como vimos, essa é a condição básica para que um predicado secundário seja licenciado.

\section{Conclusão}

A análise de Santos apresenta uma análise empírica bastante interessante. No entanto, as noções teóricas adotadas ficam aquém dos fatos apresentados. Retomando o tratamento dado aos predicados secundários em Foltran (1999), sugiro que uma teoria de intervalos de tempo associada a noções como individual e stage level é capaz de explicar o comportamento dos dados. A partir deste trabalho, seria interessante observar outros exemplos de predicação secundária em contraposição às construções de particípio absoluto para se chegar a um tratamento mais preciso do tipo de predicação envolvido no segundo caso. Apesar de não ter tratado das construções de particípio absoluto, minha intuição sempre foi no sentido de que essas construções não se caracterizam como predicados secundários. Resta observar se, confirmando-se essa intuição, a explicação poderia ser na direção dos intervalos de tempo envolvidos. No mais, concordo com Santos de que se trata de duas construções diferentes.

\section{RESUMO}

Foltran (1999) apresenta evidências que explicam as construções de predicação secundária a partir das noções stage/individual level dos predicados envolvidos. A conexão entre esses predicados é mediada por uma regra de interpretação que nos permite explicar a relação entre eles. A conexão é estabelecida por uma regra semântica que implica funções de intervalos de tempo e localização de eventos. Desse modo, é possível estabelecer uma estrutura canônica formada por dois predicados stage level, em que o predicado secundário inclui temporalmente o predicado primário. Em outra análise, San- 
tos (2000) apresenta evidências que vão de encontro a essas conclusões, mostrando a agramaticalidade de certas construções de predicação secundária com predicados stage level. O propósito deste artigo é mostrar que uma teoria baseada em intervalos de tempo explica por que alguns predicados stage level não podem ocorter numa construção de predicação secundária.

Palavras-chave: predicação secundária, construçōes participiais, intervalos de tempo.

\section{ABSTRACT}

Foltran (1999) argues in favor of explaining the constraints of secondary predication construction by the notions of stage/individual level of both predicates and by the existence of a connection between them which is mediated by a rule of interpretation that allows us to account for such constructions. In this proposal, a semantic rule establishes the connection between two predicates by functions of time intervals and event localization. Thus, we have a canonical structure formed by two stage level predicates, where the secondary predication temporally includes the matrix predicate. On the other hand, Santos (2000) presents evidence against this analysis, showing the agrammaticality of a secondary predicate construction with a stage level predicate. The aim of this paper is to show that a theory based on time interval can account for the fact that some kind of stage level predicates cannot occur in a secondary predicate construction.

Key-words: secondary predication, participial construction, time interval.

\section{REFERÊNCIAS}

COMRIE, B. Language universals and linguistic tipology. Cambridge Mass: Blackwell Publishers, 1989.

FOLTRAN, M. J. As construções de predicaçāo secundária no português do Brasil: aspectos sintáticos e semânticos. São Paulo, 1999. Tese (Doutorado) - Universidade de São Paulo.

McNALLY, L. A semantics for the English existencial construction. New York: Garland, 1997.

RAPOPORT, T. Secondary predication and lexical representation of verbs. Machine Translation, v. 5, p. 31-55, 1990. 
RAPOPORT, T. Adjunct predicate licensing and D-Structure. In: ROTHSTEIN, S. (Ed.). Syntax and Semantics 25.Perspectives on phrase structure. New York: Academic Press, 1991. p. 159-187.

SANTOS, A. L. Aspectos da estrutura sintáctica de participiais ditas absolutivas e de predicados secundários. In: ENCONTRO NACIONAL DA ASSOCIAÇĀO PORTUGUESA DE LINGÜÍSTICA, 15., 2000, Braga. Actas... Braga: APL, 2000. 